\title{
CROP CHOICE DECISION UNDER UNCERTAINTY: A CASE STUDY IN RUSSIA
}

\author{
Chetvertakov Sergey \\ Institute of Farm Economics, Thunen-Institut, Braunschweig, Germany \\ E-mail: chetvertakovsergey@gmail.com
}

\begin{abstract}
The recent expansion in corn and soybean acreage in Russia raises interest regarding the reasons behind it. A previous study by the author revealed greater profitability of corn and soybeans than the most popular crop - winter wheat. However, although shift to a cornsoybean rotation or even continuous corn is agronomically feasible, many farmers are not willing to take the related risks. Hence, the goal of this article is to derive the optimal crop portfolio accounting for relative risk aversion coefficients of farmers. On the basis of the stochastic simulation method, a new technique for risk optimization was developed. The findings indicate crop diversification is a good method to mitigate risk under Russian conditions. Only farmers preferring risk would switch to corn as a monocrop rotation.
\end{abstract}

\section{KEY WORDS}

Stochastic simulation, certainty equivalents, optimization, risk, Russia.

The agricultural sector in the Russian Federation has recovered since the beginning of the 2000s, following a significant drop in development during the 1990s. Unbalanced segments of Russian agriculture, inherited from the Soviet era, face the market and compete with other sectors of economy for investments and with foreign companies for consumers. Growing world demand and market opportunities have raised some interest in growing corn and soybeans. Rapid expansion of these crops raised concerns in the business world (Vorotnikov, 2012; Munro, 2013; Doran, 2014), but was ignored by scientists.

A prior study by the author (Chetvertakov, 2015) revealed a new hot spot of corn and soybean production - the Central Black-Soil Region (CBSR). Results of a survey proved the hypothesis that corn and soybeans are more profitable than wheat. In fact, based on accounting data alone, one would conclude that growers should move to a straight corn-soy rotation wherever agronomically feasible. However, average profitability is not the only factor in decision making regarding crop choice. Given uncertainty regarding both prices and yields, risk may impact growers' decisions. Therefore, profit maximization, the main goal of any entrepreneur, cannot be exploited uniformly. In the real world, decision makers consider both expected return and related risk in light of their personal level of risk aversion. According to Hazell (1971) and Hazell et al. (1986), disregard of risk as a factor of production sometimes leads to unacceptable results.

Hence, in determining their optimal crop portfolio, farmers should include different crop risk profiles in their decision. "Optimal" can be defined as the best equilibrium between return and risk, accounting for personal risk attitude. Such decisions usually are taken based on intuitive risk assessment and significantly depend on the personal experience of a farmer and unique features of the operation. However, recently developed scientific methods and software afford the ability to estimate different portfolio sets in an objective way and calculate possible returns in relation to observable risk.

This study aims to calculate the optimal crop portfolio in CBSR relative to a range of risk aversion for one future marketing year as a proxy: 2015-2016. This should answer a question: At what coefficient of relative risk aversion are farmers willing to increase share of the relatively new crops, corn and soybeans? Stochastic simulation is applied as a method of research.

This paper is organized as follows: The first section reviews the literature. The second section discusses the methods used in the paper. The results are outlined in the third section and the last summarizes the main findings and provides some conclusions. 


\section{LITERATURE REVIEW}

Early applied methods for risk analysis, such as stochastic efficiency, could not provide strong discriminatory power and Meyer (1977) introduced stochastic dominance with respect to a function. However, this method was overtaken by stochastic efficiency with respect to a function (Hardaker et al., 2004) and is the most powerful method to compare risky alternatives up to this time.

The concept of Certainty Equivalents (CE), exploited in the method, demands determination of risk aversion. Absolute risk aversion, defined by Pratt (1964) and Arrow (1965), lacks comparison power, because it represents risk expressed relative to the amount of risky outcome. This drawback can be overcome by relative risk aversion, which affords comparison of alternatives with different payoffs. Classification of relative risk aversion was introduced by Anderson and Dillon (1992).

Risk aversion expresses the utility function of the decision maker. For general problems, when the utility function of the decision maker is unknown, scientists apply the most popular utility functions: negative exponential, logarithmic and power (Ladanyi, 2008). However, the literature includes a great variety of functions with different features, described by Bell (1988), Saha (1993), Nakamura (1996) and Schumann et al. (2004).

The most prominent overview of agricultural risk management is provided by Hardaker et al. (2004). In their book, as in many other papers (Chavas and Holt, 1990, Hardaker et al., 2004, and Richardson and Outlaw, 2007), selection of the optimal decision stems from predetermined alternatives, which can be improved by the application of market and production risks as stochastic processes.

While production planning under uncertainty has been widely researched, there is still a gap in optimization calculation under uncertainty (Mula et al., 2006). For instance, Osaki and Batalha (2014) discuss agricultural production optimization issues under risk, but findings reflect options with regard only to deviations from the mean value as a measure of risk. According to Capolei et al. (2015), such a method has two main drawbacks: It is not sensitive to the profit shape distribution and it is symmetric and therefore penalizes higher and lower profits equally. Based on the foregoing, techniques for production optimization under uncertainty require further improvement.

\section{MATERIAL AND METHODS}

Designing the model. The main purpose of the model is derivation of the optimal crop allocation. The key output variable in this case is the net present value ${ }^{1}$ of the return to land. Therefore, the objective function will be Eq. (1)

$$
\max z=\sum_{i=1}^{n} p_{i} Y_{i} A_{i} \quad c_{i} A_{i}
$$

where $\mathrm{z}$ is return to land, $\mathrm{n}$ is the number of crops produced by a farm, $\mathrm{p}$ is the price of the $\mathrm{i}$ product, $Y_{i}$ is yield per ha of the respective crop, $A_{i}$ corresponds the crop acreage and $c_{i}$ is the cost per ha.

The aforementioned equation can be applied in linear programming, but it does not incorporate the risk issue and, for stochastic analysis purposes, the concept of CE fits better as the optimum can be found with the utility function application. This paper exploits the exponential utility function (Eq. 2) proposed by Hardaker, Richardson et al. (2004), which assumes constant relative risk aversion:

$$
C E\left(w, r_{a}(w)\right)=\ln \left\{\left(\frac{1}{n} \sum_{i}^{n} \exp \left(r_{a}(w) w_{i}\right)\right)^{-1 / r_{a}(w)}\right\}
$$

where $r_{a}(w)$ is an absolute risk aversion with respect to wealth.

\footnotetext{
${ }^{1}$ Return to land expressed in the net present value enables comparison and calculation of returns to land for different years
} 
In this paper, wealth $(w)$ and return to land $(z)$ are assumed to be equal. For the purpose of convenience, the absolute risk aversion $r_{a}$ will be substituted by the relative risk aversion $r_{r}$ and expected money value $E$ as $r_{a}=\frac{r_{r}}{E}$ (Pratt, 1964; Arrow, 1965). This expression is preferable as relative risk aversion is not sensitive to units of outcome measurement and the results therefore are directly comparable (Meyer and Meyer, 2005).

It follows from Eq. (1) that the model requires cost, yield and price information. In this study, the author focuses only on the main cash crops of the CBSR: corn, spring barley, spring and winter wheat, sunflowers and soybeans. In 2014 , these crops covered $84 \%$ of all land planted to cash crops. Sugarbeet, which also is an important cash crop for the region (occupied $7 \%$ of cash crop acreage), is not included because this crop's feasibility is highly correlated with distance to a processing facility and, moreover, this sector is highly monopolized.

The type of necessary data depends on the nature of the analysis; calculations can be done in a retrospective or prospective manner. Retrospectivity assumes the search for the best option is based solely on historical data and the result also will be the best choice for the future. In other words, the calculation indicates the best option and its outcome in the past and assumes following this track in a future will provide the maximum profit with the lowest risk. The prospective calculation, on the other hand, assumes some variables will not have an identical distribution in the future and applies expected changes. In this research, prices and costs ignore the historical values and can be adjusted in the forecast. Yield is assumed to have the same distribution as in the past. Both options are outlined in the paper.

For convenience, further explanation of the model's construction is divided by blocks.

Block of costs. Cost data are obtained from the agri benchmark typical farm in the Voronezh region (part of the CBSR). Data from typical farms generate in-depth insights regarding the economics of the main crops produced in Russia. This method is used by agri benchmark Cash Crop, a non-profit global network of agricultural economists, advisors, producers and specialists in key sectors of crop value chains (agri benchmark, 2014).

Official yield statistics show changes in the production pattern in 2004, when corn and soybeans began to expand. Therefore, the data should embrace the years of 2004-2014. Cost data of the typical farm in the agri benchmark database were collected for 2009-2014. Costs for missed years are calculated by deflation of 2009 costs.

The aforementioned cost calculation is applied in the retrospective calculation. For the prospective calculation, the 2014 data are inflated according to the price change in agricultural inputs in 2015. The relative price change was provided by the Institute for Agricultural Market Studies in Russia.

There is one more issue linked with the cost data: the need to calculate fixed and variable costs separately. Moreover, such costs may vary relative to a crop's share in a rotation and a significant deviation from the original ratio can occur because of the lack of labor and equipment. Nevertheless, Russian agriculture in this region has a great supply of contractors. The climatic conditions in the western part of Russia allow such contractors to begin seasonal work in the south and work their way north to the CBSR and beyond, working greater acreage than a single farm.

The cost of contractors is comparable to farmers' own costs and in the analysis, they are assumed to be identical. Therefore, costs consist of two variable elements: the direct input cost per ha (seeds, fertilizers and pesticides) and operating cost per ha (labor, machinery and diesel and other energy cost). Other on-farm costs not related to crops are not included as they do not play a role in the net return comparison between crops.

Another calculation method was applied to soybeans. The sample typical farm does not grow this crop so an average production cost was taken from a survey conducted by the author (Chetvertakov, 2015). For retrospective analysis, cost data were deflated to derive figures for the entire period of calculation. For the prospective analysis, soybean production costs are calculated in the same manner as other crops.

Block of yields. Yield data for the representative typical farm do not exist for a long period (only 2009-2014, as mentioned earlier) and the study uses official statistics at the 
farm's county level (GKS regional 2015). The county statistics present the most detailed level of official data and better reflect variability in yields than statistics at a regional or national level.

Retrospective analysis applies empirical yield data. For the prospective analysis, yield is treated stochastically and is subjected to Monte Carlo simulation. To achieve a better predictability of yield distribution, de-trending was considered, using residuals after detrending in the simulation. However, sparse data do not allow such procedure. Therefore, all yields are simulated according to the historical data.

Block of prices. Retrospective analysis applies historical prices. For 2009-2014, the prices of the typical farm are applied. For the rest of the period, monthly prices were obtained from the official statistics on the regional level (UniSIS, 2015) and calculated as the average for the marketing year. Prices for soybeans were defined by official statistics only.

Determination of prices for the prospective analysis is one of the most challenging aspects of the analysis. Market risks play a significant role in agriculture and are difficult to predict. This risk may be mitigated by insurance, which is commonly used in much of the world (Vilhelm, 2011). However, the market for insurance is underdeveloped in Russia: In 2014 , only $17.7 \%$ of the total acreage was insured (NAAI, 2015). Hedging instruments also are not common in Russia (e.g., a futures market does not exist in the state). Therefore, most farmers rely on the spot market. Adding to price uncertainty are the significant depreciation of the national currency since 2014 and the establishment of export fees for wheat (Gov, 2015).

Given such factors, expert estimation of future prices is the best proxy. For this task, two experts were asked to make projections of the minimum, maximum and the most probable prices of selected crops (one expert provided expertise with regard to small grains and corn and the other for oilseeds) for the 2015-2016 agricultural year. This evaluation was used to derive PERT distribution, where prices are assumed to be a stochastic value.

Calculation. All monetary data are expressed in the national currency, the ruble. The rationale for this decision is based on two factors:

a) All costs and cash payments in Russia are implemented in rubles. Note, however, that given high fluctuations of exchange rates and the time lag between expenditure on inputs and receipt of proceeds, calculations will not reflect a true market picture.

b) Wheat export fees also are measured in local currency and incorporate exchange rate risk.

Conversion of monetary values to other currencies is possible, but would require additional complicated adjustments.

The acreage values are rounded with precision of 10 ha. This provides better handling of figures and does not lead to a considerable change in the results.

Retrospective maximization. Multiplication of yields per/ha and prices/ton for each year gives the revenues per ha. Deducting costs provides the net return per ha of selected crops for 11 years: 2004-2014. Then, to calculate crop portfolio outcome, the net return/ha of every crop of each year was multiplied by the acreage (initially assigned 10 hectares each) and net return of all crops was summarized in the farm net return. All return values were converted to the net present value of 2014.

The next step involves the calculation of CE according to equation 2. The best crop portfolio assumes the highest CE. This task can be performed by the Solver Add-in for Microsoft Excel by changing acreages for each crop. The maximization task is the subject for constraints:

1) $A_{i} \geq 0 \quad i(1, \ldots, n)$

2) $\sum_{i=1}^{n} A_{i} \leq 20000 \quad i(1, \ldots, n)$

3) $A_{\text {small grains }} \leq 60 \% \times \sum_{i=1}^{n} A_{i}$

4) $A_{\text {sunflower }} \leq 14.3 \% \times \sum_{i=1}^{n} A_{i}$

The first constraint is non-negative acreage values. The second is that total acreage cannot exceed 20,000 ha (total cropland of the typical farm). The third and fourth constraints are agronomical rigid rules for this area, which can be violated for a short-term, but should be respected for a long-term production. 
According to the classification of the degree of risk aversion developed by Anderson and Dillon (1992), the relative risk aversion is varied from 0 to 4 , reflecting gradation from risk neutrality to extremely risk averse. The author also applies negative risk aversion coefficients up to -4 to reflect risk lovers. Changing the relative risk aversion coefficient provides the most profitable crop portfolio according to risk.

Prospective maximization. Prospective maximization assumes stochastic variability of yield and prices, but does not cancel their dependence. Therefore, in the first stage, historical yields and prices across all crops were estimated with regard to correlations. For this task we can apply copula correlation with the help of ModelRisk by Vose Software. Because of the sparse data, it is difficult to judge the form of the correlation. Hence, to reflect the most general, linear form of correlation, a multi-normal copula is employed here.

Switching from the empirical data to the Monte Carlo simulation demands distribution estimation. For yields, empirical distribution was fitted. Prices, as was mentioned in the block of price data, take the PERT distribution according to the expert estimation. Simulation has been performed according to distributions and assigned copulas with 30,000 samples in Microsoft Excel with the ModelRisk add-in. Simulated values were validated by correlation test: The correlation matrix of simulated values was compared with the correlation matrix of the original data (performed with Simetar add-in for Microsoft Excel). Calculated Student's ttest statistics indicate high validity of the data and estimated coefficients do not exceed critical values, with the confidence level equal to $99.9 \%$. A comparison test of two data series (only for empirical and simulated yields) failed to reject that the mean vectors are equal.

Multiplication of simulated yields and prices provides the revenues and subtraction of costs (derivation explained earlier) gives net return distribution. Search for a crop rotation with the highest CE follows the same pattern as for the retrospective maximization. The only difference is that the data represent not the historical values, but simulated ones.

\section{RESULTS OF RESEARCH}

Retrospective maximization. The application of the model reveals the optimal crop acreage allocation according to the relative risk aversion coefficients in table 1 . Risk-seeking farmers would choose corn as a monocrop as it provides potentially the highest maximum net return, equal to $764 \mathrm{mln}$. rubles per farm (with 20,000 ha) or 38.2 thousand rubles per ha (net present value of 2014). With the highest net return, such a farmer also would be subject to the greatest losses $-213 \mathrm{mln}$. rubles per farm (10,650 rubles per ha).

The optimal decision for a risk-neutral person would be to distribute $14.3 \%$ of acreage to sunflower, which is the limitation objective. More risk-averse farmers should distribute acreage also to spring barley and winter wheat. Farmers with the relative risk aversion equal to 1 should consider growing five out of six investigated crops. Producers with higher risk aversion would increase acreage of soybeans and winter wheat and decrease acreage of corn and spring barley, with the extremely risk averse reaching zero. Spring wheat would not be included in any crop portfolio.

The differences in crop portfolio sets are plotted in the Fig. 1. The mean changes slightly across variants, but minimum and maximum net return lines are seeking each other with increasing risk aversion. Certainty equivalent comes closer to the maximum return for risk lovers and vice versa for risk-avoiding people and intersects the mean line at zero (risk neutral).

Prospective maximization. Results of the CE maximization for 2015-2016 on the basis of prospective calculations have lower variability. Similar to the retrospective calculation, risk lovers would grow only corn (table 2) and expect average net return $163 \mathrm{mln}$. rubles with maximum and minimum net returns per farm of 700 and -447 mln. rubles. However, farmers with relative risk-aversion coefficients in a range equal to -0.5 to 0.5 would increase winter wheat and sunflower acreages to higher limits, leading to a considerable decrease in possible losses, namely to $-199 \mathrm{mln}$. rubles per farm. At the same time, probability of having a negative net return drops from 0.36 to 0.1 (Appendix 2). Farmers with higher risk aversion would switch to soybeans instead of corn. Crop farmers with a relative risk aversion equal to 
2 and higher would keep winter wheat and sunflowers on the higher limits and grow soybeans on residual acreage. That mix potentially can provide the maximum net return of $668 \mathrm{mln}$. rubles and $133 \mathrm{mln}$. rubles of losses with the probability of getting a negative net return at 0.09 . Spring wheat and barley should not be grown across all risk-aversion options in order to reach the optimal portfolio.

In general, indicators in the prospective analysis follow the same pattern as the retrospective one (Fig. 2). However, the minimum and the maximum net return lines have slightly different forms: In the retrospective analysis, the maximum net return curved more across relative risk-aversion coefficients than the minimum net return. It is the other way around in the prospective analysis. This means that in the first variant of calculations, risk reduction resulted in a more significant downturn in potential maximum net return than potential negative net return mitigation. In the second variant of analysis, diminishment of potential losses to reduce risk was accompanied by only a slight decline in maximum net return.

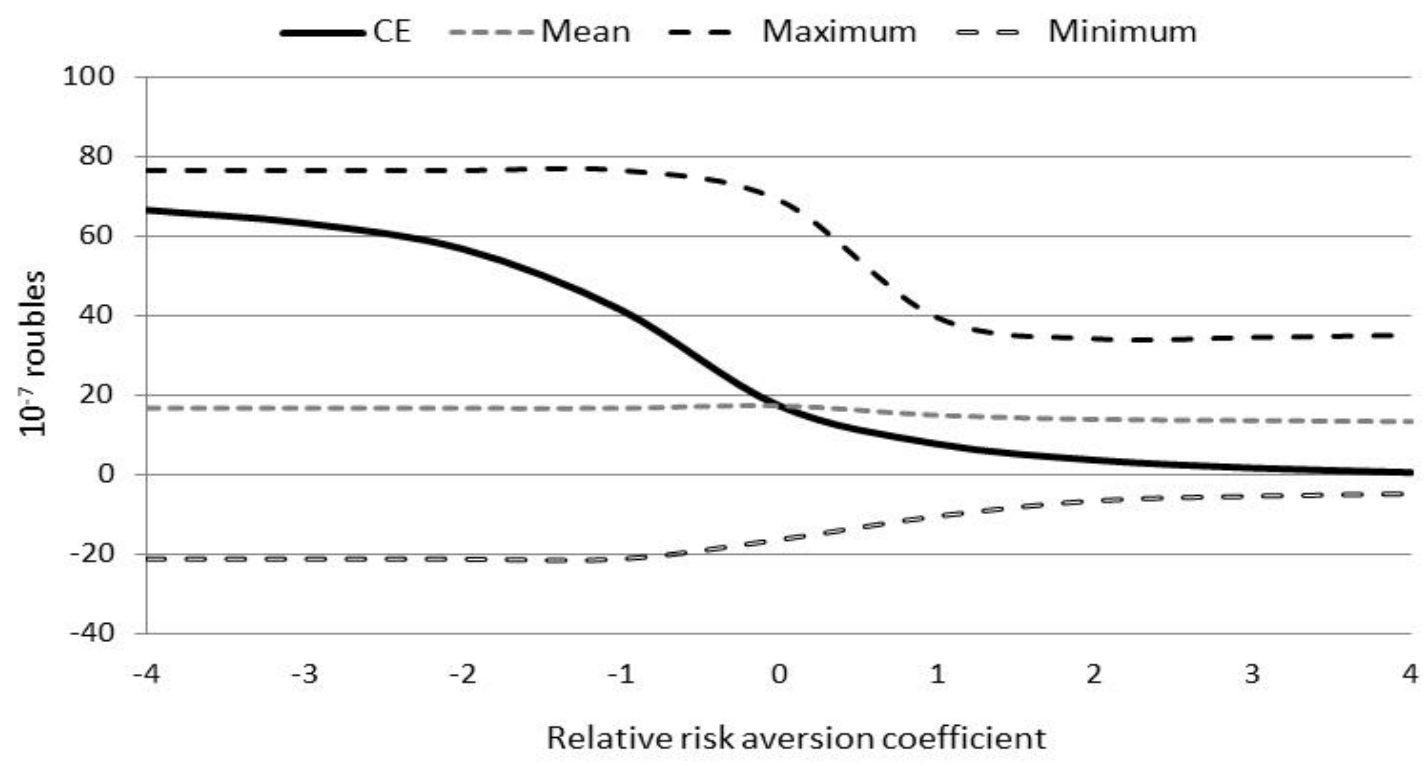

Figure 1 - Optimum net return (retrospective basis) frontier with respect to the risk aversion

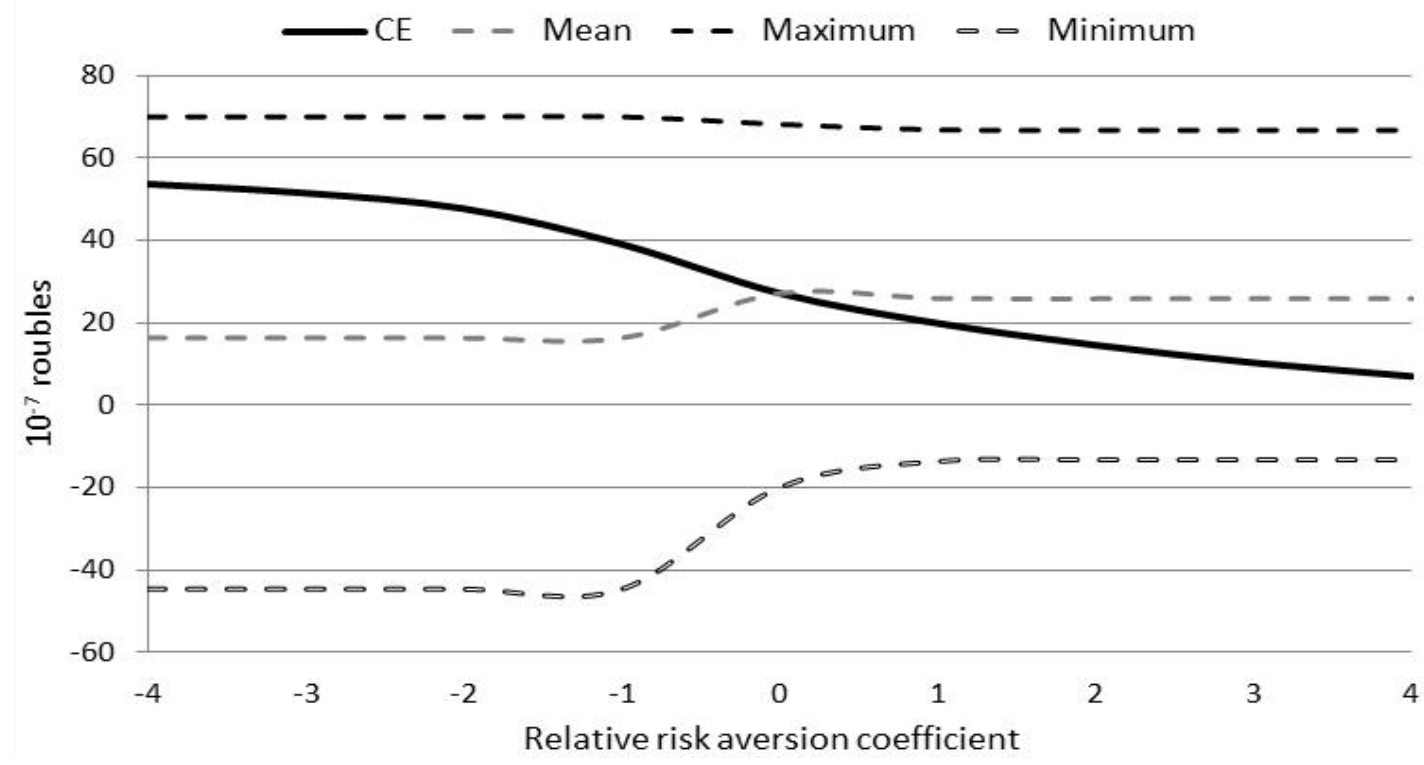

Figure 2 - Optimum net return (prospective basis) frontier with respect to the risk aversion 
RJOAS, 7(55), July 2016

Table 1 - Optimal crop portfolio set on the retrospective basis with respect to risk aversion

\begin{tabular}{|c|c|c|c|c|c|c|c|c|c|c|}
\hline \multirow{2}{*}{$\mathrm{Rr}$} & \multicolumn{6}{|c|}{ Acreage } & \multirow{2}{*}{ CE } & \multirow{2}{*}{ Mean } & \multirow{2}{*}{ Minimum } & \multirow{2}{*}{ Maximum } \\
\hline & Soybeans & Corn & Winter wheat & Sunflower & Spring wheat & Spring barley & & & & \\
\hline \multicolumn{11}{|c|}{ units } \\
\hline- & ha & ha & ha & ha & ha & ha & $10^{\prime}$ rubles & $10^{\prime}$ rubles & $10^{\prime}$ rubles & $10^{\prime}$ rubles \\
\hline-4.00 & 0 & 20,000 & 0 & 0 & 0 & 0 & 66.5 & 16.6 & -21.3 & 76.4 \\
\hline-3.00 & 0 & 20,000 & 0 & 0 & 0 & 0 & 63.2 & 16.6 & -21.3 & 76.4 \\
\hline-2.00 & 0 & 20,000 & 0 & 0 & 0 & 0 & 56.7 & 16.6 & -21.3 & 76.4 \\
\hline-1.00 & 0 & 20,000 & 0 & 0 & 0 & 0 & 41.3 & 16.6 & -21.3 & 76.4 \\
\hline-0.50 & 0 & 20,000 & 0 & 0 & 0 & 0 & 28.6 & 16.6 & -21.3 & 76.4 \\
\hline $0.00^{\mathrm{b}}$ & 0 & 17,140 & 0 & 2,860 & 0 & 0 & 17.2 & 17.2 & -16.4 & 69.0 \\
\hline 0.25 & 0 & 13,710 & 0 & 2,860 & 0 & 3,430 & 13.5 & 16.6 & -14.0 & 59.1 \\
\hline 0.50 & 0 & 9,340 & 0 & 2,860 & 0 & 7,800 & 11.1 & 15.7 & -12.9 & 46.5 \\
\hline 0.75 & 0 & 7,950 & 790 & 2,860 & 0 & 8,400 & 9.2 & 15.4 & -12.2 & 42.4 \\
\hline 1.0 & 1,880 & 5,890 & 2,620 & 2,860 & 0 & 6,750 & 7.6 & 14.9 & -10.5 & 39.4 \\
\hline 1.50 & 4,440 & 3,440 & 5,480 & 2,860 & 0 & 3,780 & 5.2 & 14.2 & -8.2 & 36.4 \\
\hline 2.00 & 5,280 & 2,250 & 8,410 & 2,860 & 0 & 1,200 & 3.6 & 13.9 & -6.6 & 34.1 \\
\hline 2.50 & 5,490 & 1,590 & 10,060 & 2,860 & 0 & 0 & 2.4 & 13.7 & -5.9 & 34.3 \\
\hline 3.00 & 5,600 & 1,000 & 10,540 & 2,860 & 0 & 0 & 1.6 & 13.5 & -5.5 & 34.5 \\
\hline 3.50 & 5,620 & 460 & 11,060 & 2,860 & 0 & 0 & 1.0 & 13.4 & -5.2 & 34.7 \\
\hline 4.00 & 5,590 & 0 & 11,550 & 2,860 & 0 & 0 & 0.5 & 13.3 & -4.9 & 35.0 \\
\hline
\end{tabular}

Table 2 - Optimal crop portfolio set on the prospective basis with respect to risk aversion

\begin{tabular}{|c|c|c|c|c|c|c|c|c|c|c|c|}
\hline \multirow[b]{2}{*}{$\mathrm{Rr}$} & \multicolumn{7}{|c|}{ Acreage } & \multirow{2}{*}{ CE } & \multirow[b]{2}{*}{ Mean } & & \multirow[b]{2}{*}{ Maximum } \\
\hline & Soybeans & Corn & Winter wheat & Sunflower & Spring wheat & Spring barley & & & & Minimum & \\
\hline \multicolumn{12}{|c|}{ units } \\
\hline - & ha & ha & ha & ha & ha & ha & & $10^{\prime}$ rubles & $10^{\prime}$ rubles & $10^{\prime}$ rubles & $10^{\prime}$ rubles \\
\hline-4.00 & 0 & 20,000 & 0 & 0 & & 0 & 0 & 53.7 & 16.3 & -44.7 & 70.0 \\
\hline-3.00 & 0 & 20,000 & 0 & 0 & & 0 & 0 & 51.5 & 16.3 & -44.7 & 70.0 \\
\hline-2.00 & 0 & 20,000 & 0 & 0 & & 0 & 0 & 47.7 & 16.3 & -44.7 & 70.0 \\
\hline-1.00 & 0 & 20,000 & 0 & 0 & & 0 & 0 & 39.1 & 16.3 & -44.7 & 70.0 \\
\hline-0.50 & 0 & 5,140 & 12,000 & 2,860 & & 0 & 0 & 30.9 & 27.2 & -19.9 & 68.2 \\
\hline $0.00^{c}$ & 0 & 5,140 & 12,000 & 2,860 & & 0 & 0 & 27.2 & 27.2 & -19.9 & 68.2 \\
\hline 0.50 & 0 & 5,140 & 12,000 & 2,860 & & 0 & 0 & 23.3 & 27.2 & -19.9 & 68.2 \\
\hline 0.75 & 2,510 & 2,630 & 12,000 & 2,860 & & 0 & 0 & 21.4 & 26.5 & -16.7 & 67.5 \\
\hline 1.00 & 4,850 & 290 & 12,000 & 2,860 & & 0 & 0 & 19.9 & 25.9 & -13.7 & 66.8 \\
\hline 2.00 & 5,140 & 0 & 12,000 & 2,860 & & 0 & 0 & 14.6 & 25.9 & -13.3 & 66.8 \\
\hline 3.00 & 5,140 & 0 & 12,000 & 2,860 & & 0 & 0 & 10.3 & 25.9 & -13.3 & 66.8 \\
\hline 4.00 & 5,140 & 0 & 12,000 & 2,860 & & 0 & 0 & 7.0 & 25.9 & -13.3 & 66.8 \\
\hline
\end{tabular}

${ }^{\mathrm{b}}$ To be able to run calculation, author used $10^{-6}$ instead of null.

${ }^{\mathrm{c}}$ To be able to run calculation, author used $10^{-6}$ instead of null. 


\section{CONCLUSIONS}

Crop return data cannot be the only factor exploited for decision making. New crop for CBSR of Russia such as corn provide higher returns in comparison to winter wheat, but bear risk as well. Corn as a monocrop can be optimal only for risk lovers. Slightly risk-averse farmers, which usually can be expected, would diversify production to diminish potential losses. Poor development of insurance service and governmental support force farmers in Russia to use crop portfolio diversification as a risk reducer. In the case of status quo, a future shift to a corn-soybeans rotation or corn as a monocrop, as seen in some parts of the United States (Taheripour et al., 2015), is unlikely.

Performed calculations are not without flaws: Some data come from different sources and Russian crop production varies considerably among farmers, so that a single farm's ability to reflect production patterns of even a single region is limited. However, despite the scarcity of data, the explored manner of risk handling clarifies uncertainty in a reliable way.

Better risk management will help businesses operate in a more efficient manner. As explained in this paper, analysis can be used not only to rank alternatives to be considered by a decision maker, but can be exploited as a tool for broader solutions when the decision maker finds it difficult or is unable to formulate all alternatives. Improved analysis affords handling uncertainty to find the best solution in given circumstances.

Both approaches used in the paper can be easily adopted and applicable for risk assessment and strategy development in the private sector as well as by policy makers in the public sector. The combination of linear programming and dynamic methods of calculation does not require advanced knowledge of dedicated software; all calculations here have been performed in Microsoft Excel.

\section{ACKNOWLEDGEMENTS}

This paper was prepared with the financial support of the agri benchmark Cash Crop Network (http://www.agribenchmark.org). The author grateful to Prof. Dr. Oliver Musshoff, Dr. Yelto Zimmer and Dr. Frank Offermann for very helpful comments and advice on an early draft of this paper and to Linda Smith for language corrections of the paper.

\section{REFERENCES}

1. agri benchmark (2014). Who we are. http://www.agribenchmark.org/agri\%20benchmark/ who-we-are.html Accessed 12 May 2014.

2. Anderson, J. R., Dillon, J. L. (1992). Risk analysis in dryland farming systems. Food \& Agriculture Org.

3. Arrow, K.J. (1965). Aspects of the Theory of Risk-Bearing. - Yrjö Jahnssonin Säätiö, Academic Bookstore, Helsinki.

4. Bell, D. E. (1988). One-switch utility functions and a measure of risk. Management science 34(12): 1416-1424.

5. Capolei, A., Foss, B., \& Jørgensen, J. B. (2015). Profit and Risk Measures in Oil Production Optimization. IFAC-PapersOnLine, 48(6), 214-220.

6. Chavas, J. P., Holt, M. T. (1990). Acreage Decisions under Risk - the Case of Corn and Soybeans. American Journal of Agricultural Economics 72(3): 529-538.

7. Chetvertakov, S. (2015) Corn and soy in Russia: the latest fad or a new cash cow? Proceedings of the 24th International Scientific Conference Agrarian Perspectives XXIV. - Global Agribusiness and Rural Economy: 199-207. DOI: 10.13140/RG.2.1.1054.7929

8. Doran, T. (2014) Corn, Soybean Export Locomotive Rolls On. AgriNews, 15 April 2014. http://agrinews-pubs.com/Content/News/Markets/Article/Corn--soybean-exportlocomotive-rolls-on-/8/26/10161 Accessed 10 May 2014.

9. GKS regional (2015). http://www.gks.ru/dbscripts/munst/munst20/DBInet.cgi Accessed 19 August 2015.

10. Gov (2015). Resolution of the Russian Government "About Establishment of the export customs duty rate on wheat." http://government.ru/docs/18291/ Accessed 23 June 2015. 
11. Hardaker, J. B., Richardson, J. W., Lien, G., and Schumann, K. D. (2004). Stochastic Efficiency Analysis with Risk Aversion Bounds: A Simplified Approach. Australian Journal of Agricultural and Resource Economics, 48(2): 253-270.

12. Hardaker, J. B., Huirne, R. B., Anderson, J. R., and Lien, G. (2004). Coping with Risk in Agriculture. CABI Publishing.

13. Hazell, P. B. (1971). A Linear Alternative to Quadratic and Semivariance Programming for Farm Planning Under Uncertainty. American Journal of Agricultural Economics 53(1): 53-62.

14. Hazell, P. B., Norton, R. D. (1986). Mathematical Programming for Economic Analysis in Agriculture. New York: Macmillan.

15. Ladanyi, M. (2008). Risk Methods and Their Applications in Agriculture. Applied Ecology and Environmental Research 6(1): 147-164.

16. Meyer, D. J., and Meyer, J. (2005). Relative Risk Aversion: What Do We Know? Journal of Risk and Uncertainty 31(3): 243-262.

17. Meyer, J. (1977). Choice Among Distributions. Journal of Economic Theory 14(2): 326336.

18. Mula, J., Poler, R., Garcia-Sabater, J., and Lario, F. C. (2006). Models for Production Planning Under Uncertainty: A Review. International Journal of Production Economics 103(1): 271-285.

19. Munro, E. (2013). Strong Corn Competition from Russia, Ukraine. Corn and Soybean Digest, 16 December 2013. http://cornandsoybeandigest.com/issues/strong-corncompetition-russia-ukraine Accessed 9 May 2014.

20. NAAI (2015). International Round Table of NAAl: Agricultural Insurance in Russia Prepares for a New Stage. National Association of Agriculture Insurers. http://www.naai.ru/eng/press-

tsentr/nsa_news/international_round_table_of_naai_agricultural_insurance_in_russia_pre pares_for_a_new_stage/ Accessed 23 June $20 \overline{0} 15$.

21. Nakamura, $\bar{Y}$. (1996). Sumex Utility Functions. Mathematical Social Sciences 31(1): 3947.

22. Osaki, M., and Batalha, M. O. (2014). Optimization Model of Agricultural Production System in Grain Farms Under Risk in Sorriso, Brazil. Agricultural Systems 127: 178-188.

23. Pratt, J.W. (1964). Risk Aversion in the Small and in the Large. Econometrica 32: 122136.

24. Richardson, J. W. and Outlaw, J. L. (2007). Training Commercial Farmers How to Analyse and Rank Risky Alternatives. In Proceedings of the 16th International Farm Management Association Congress.

25. Saha, A. (1993). Expo-power Utility: A 'Flexible' Form for Absolute and Relative Risk Aversion. American Journal of Agricultural Economics 75(4): 905-913.

26. Schumann, K. D., Richardson, J. W., Lien, G., Hardaker, J. B. (2004). Stochastic efficiency analysis using multiple utility functions. Paper presented at the AAEA Annual Meeting.

27. Taheripour, F., Fiegel, J., Tyner, W. E., (2015). Development of Corn Stover Biofuel: Impacts on Corn and Soybean Markets and Crop Rotation. Sustainable Agriculture Research, 5(1), 1.

28. UniSIS (2015). Unified Interdepartmental Statistical Information System of the Russian Federation. http://www.fedstat.ru/ Accessed 19 August 2015.

29. Vilhelm, V. (2011). The Role of Public Support of Risk Management in Agriculture. In Proceedings of the 20th International Scientific Conference Agrarian Perspectives, Prague, pp. 179-186. ISBN 978-80-213-2196-0

30. Vorotnikov, V. (2012). Russia is Producing more Soybeans and Corn. All About Feed, 2 March 2012; updated 6 August 2012. http://www.allaboutfeed.net/Nutrition/RawMaterials/2012/3/Russia-is-producing-more-soybeans-and-corn-AAF012875W/ Accessed 10 May 2014. 
APPENDIX 1 - CUMULATIVE DISTRIBUTION FUNCTION OF NET RETURN RELATIVE TO RISK AVERSE WITH RETROSPECTIVE CALCULATION

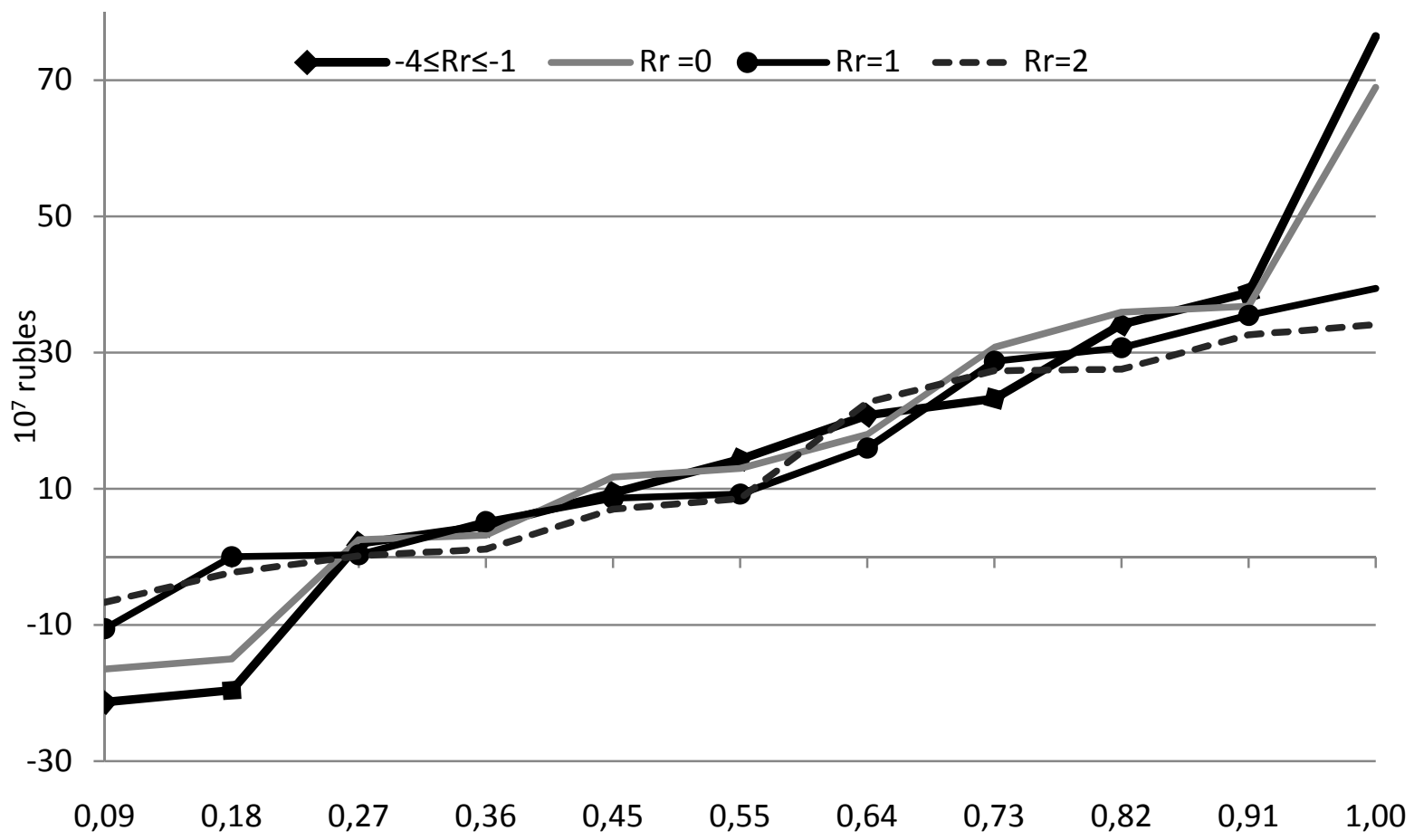

APPENDIX 2 - CUMULATIVE DISTRIBUTION FUNCTION OF NET RETURN RELATIVE TO RISK AVERSE WITH PROSPECTIVE CALCULATION

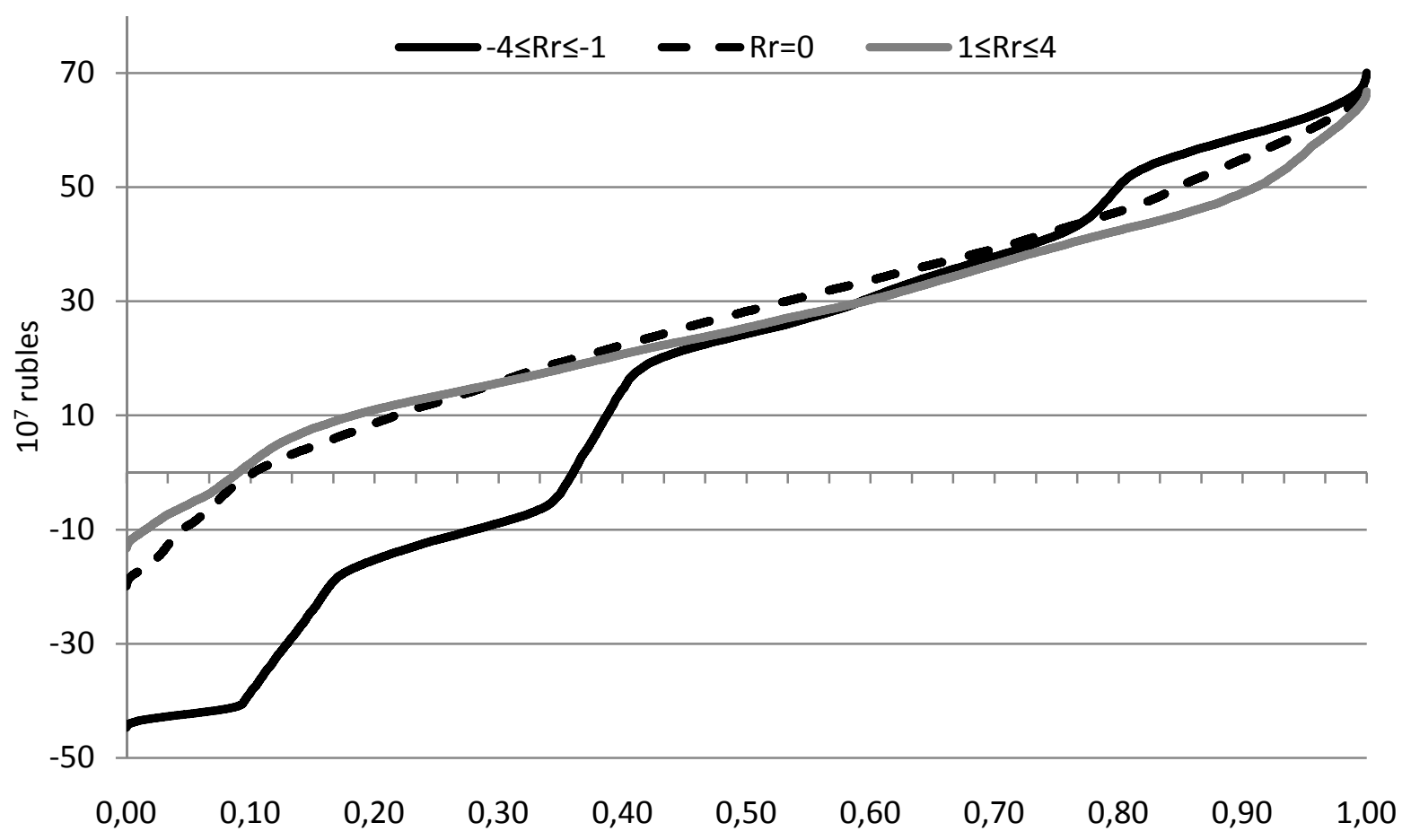

